\title{
A model for transmission of the H3K27me3 epigenetic mark
}

\author{
Klaus H. Hansen, Adrian P. Bracken, Diego Pasini, Nikolaj Dietrich, Simmi S. Gehani, Astrid Monrad, \\ Juri Rappsilber, Mads Lerdrup and Kristian Helin
}

Nature Cell Biol. 10, 1291-1300 (2008); published online 19 October 2008; corrected after print 28 October 2008

In the version of this article initially published, the order of the labels siRNA cyclophilin B and siRNA SUZ12 in figure 5 and GAL4-EZH2 ${ }^{\text {wT }}$ and GAL4-EZH2 ${ }^{\triangle \mathrm{SET}}$ in figure $7 \mathrm{a}$ were reversed. The corrected panels are shown below. These errors have also been corrected in the HTML and PDF versions of the article.

Figure 5

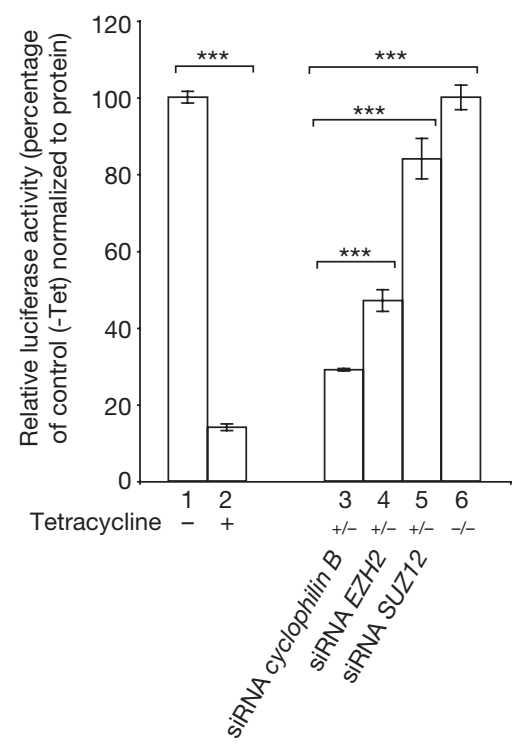

Figure 7

a

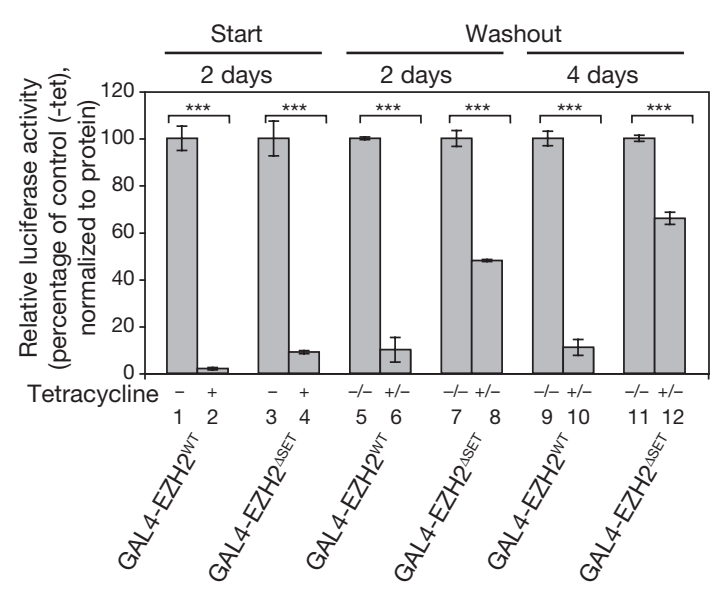

